\title{
Review Article \\ The Utility of Iron Chelators in the Management of Inflammatory Disorders
}

\author{
C. Lehmann, ${ }^{1,2,3}$ S. Islam, ${ }^{1,3,4}$ S. Jarosch, ${ }^{1}$ J. Zhou, ${ }^{1,2}$ D. Hoskin, ${ }^{2,5}$ \\ A. Greenshields, ${ }^{5}$ N. Al-Banna, ${ }^{1}$ N. Sharawy, ${ }^{1,6}$ A. Sczcesniak, ${ }^{3}$ M. Kelly, ${ }^{1,3}$ \\ K. Wafa, ${ }^{1}$ W. Cheliak, ${ }^{7}$ and B. Holbein ${ }^{7}$ \\ ${ }^{1}$ Department of Anesthesia, Pain Management and Perioperative Medicine, Dalhousie University, \\ 5850 College St., Halifax, NS, Canada B3H 1 X5 \\ ${ }^{2}$ Department of Microbiology and Immunology, Dalhousie University, 5850 College Street, Halifax, NS, Canada B3H 1 X 5 \\ ${ }^{3}$ Department of Pharmacology, Dalhousie University, 5850 College St., Halifax, NS, Canada B3H 1 X5 \\ ${ }^{4}$ Department of Pharmacy, East West University, Plot No. A/2, Jahurul Islam City, Aftabnagar, Dhaka 1219, Bangladesh \\ ${ }^{5}$ Department of Pathology, Dalhousie University, 5850 College St., Halifax, NS, Canada B3H 1 X5 \\ ${ }^{6}$ Department of Physiology, Faculty of Medicine, Cairo University, 1 Al-Saray St., Cairo 11559, Egypt \\ ${ }^{7}$ Chelation Partners Inc., 1411 Oxford St., Halifax, NS, Canada B3H $3 Z 1$ \\ Correspondence should be addressed to C. Lehmann; chlehmann@dal.ca
}

Received 20 June 2014; Revised 1 September 2014; Accepted 1 September 2014

Academic Editor: Yung-Hsiang Chen

Copyright (C) 2015 C. Lehmann et al. This is an open access article distributed under the Creative Commons Attribution License, which permits unrestricted use, distribution, and reproduction in any medium, provided the original work is properly cited.

\begin{abstract}
Since iron can contribute to detrimental radical generating processes through the Fenton and Haber-Weiss reactions, it seems to be a reasonable approach to modulate iron-related pathways in inflammation. In the human organism a counterregulatory reduction in iron availability is observed during inflammatory diseases. Under pathological conditions with reduced or increased baseline iron levels different consequences regarding protection or susceptibility to inflammation have to be considered. Given the role of iron in development of inflammatory diseases, pharmaceutical agents targeting this pathway promise to improve the clinical outcome. The objective of this review is to highlight the mechanisms of iron regulation and iron chelation, and to demonstrate the potential impact of this strategy in the management of several acute and chronic inflammatory diseases, including cancer.
\end{abstract}

\section{Introduction}

Although iron exists in abundance in the earth's crust and the environment, iron is found in relatively low concentrations in aqueous systems under aerobic conditions. Fe occurs in two main oxidation states: the reduced $\mathrm{Fe}^{2+}$ (Fe II, ferrous) and the oxidized $\mathrm{Fe}^{3+}$ (Fe III, ferric) form. Iron represents an essential trace element for almost all forms of life; however, iron has paradoxical properties. It readily accepts and donates electrons, converting between the more soluble ferrous form and the insoluble ferric form, and thus plays an integral role in electron transfer and oxygen transport as well as adenosine triphosphate and deoxyribonucleic acid synthesis [1]. However, iron can also catalyze the formation of reactive oxygen species (ROS) via redox reactions. The Fenton and
Haber-Weiss reactions of $\mathrm{H}_{2} \mathrm{O}_{2}$ with $\mathrm{Fe}^{2+}$ generate hydroxyl radicals that promote oxidative stress and are responsible for lipid, protein, and DNA damage. Importantly, dysregulated iron homeostasis is associated with progressive inflammatory and degenerative diseases, as well as cancer [2]. Iron and its homeostasis are intimately tied to the inflammatory response. Iron withdrawal is part of the natural innate immune response in inflammation [3]. During inflammation and infection a "hypoferremic response" is observed (anemia of inflammation) [4].

Given the role of iron in development of inflammatory diseases, pharmaceutical agents targeting this pathway promise to improve the clinical outcome. The objective of this review is to highlight the mechanisms of iron regulation and iron chelation and to demonstrate the potential impact of this 
approach in the management of several acute and chronic inflammatory diseases, including cancer. For this purpose, we reviewed the literature regarding experimental and clinical evidence for iron-related anti-inflammatory strategies and discuss implications and limitations of iron removal in inflammation.

\section{Basic Mechanisms}

2.1. Iron Absorption and Regulation in the Human Body. Dietary iron uptake is closely regulated, which is critical to cell physiology and to ensure minimal concentrations of potentially dangerous free intracellular iron. Mechanisms for iron homeostasis are complex compared to other metals, which are typically controlled by a simple elimination process [5]. Iron requirements are high during infancy, childhood, and pregnancy [6]. Absorption declines to around $1 \mathrm{mg} /$ day in men and $2 \mathrm{mg} /$ day in women when growth declines [5]. Both heme and nonheme iron can be utilized by the intestinal epithelium. Heme iron is abundant in meat as hemeprotein and myoglobin, released from hemeprotein by proteolytic enzymes in the stomach and small intestine. Nonheme iron crosses the apical brush border membrane of enterocytes after conversion into ferrous iron by duodenal cytochrome $B$ [7]. Iron has two fates according to the requirement of the body once within the enterocytes. When iron demand in the body is low, iron remains sequestered in the enterocyte within ferritin as a mechanism of iron storage. When the iron demand of the body is high, iron crosses the basolateral membrane via the iron export protein ferroportinl (FPN) and enters the circulation, ultimately binding to transferrin. FPN is found in the basolateral membrane of the enterocytes and in large quantities on macrophages [8]. Ferroxidase activity of ceruloplasmin or hephaestin is required to load iron safely onto transferrin [9]. To mitigate iron losses from the body from shedding of epithelial cells and menstruation, the body must absorb an equivalent amount of iron from the gut, maintaining an overall iron balance.

In total, the human body contains approximately 3 to $4 \mathrm{~g}$ of iron in the form of both heme and nonheme iron [10]. Human hemoglobin accounts for $65 \%$ of total body iron, while $25 \%$ of body iron is bound to iron storage proteins ferritin and hemosiderin. The remaining $10 \%$ are constituents of myoglobin, cytochrome, and other iron-containing enzymes [11]. Only about $0.1 \%$ of body iron is bound to transferrin and this circulates as a soluble exchangeable pool in the plasma. Tissue macrophages phagocytize senescent red blood cells to recover, turnover, and recycle iron. This recycling of iron by macrophages is 20 -fold greater than the amount of iron absorbed daily by the intestine. Iron absorption by enterocytes and the recycled iron efflux from macrophages are controlled by hepcidin, a key iron regulatory hormone produced by hepatocytes $[12,13]$. It limits the cellular iron efflux by binding to FPN and facilitates its internalization and ultimate degradation [14]. Hepcidin expression is increased in times when iron stores are sufficient and is decreased when the requirement of iron is high. Poor gut iron absorption can be predicted by elevated hepcidin level [15]. The regulation of iron absorption is critical because humans do not have physiological pathways for its excretion. Hepcidin levels are increased during infection and inflammation. Its release is upregulated in response to inflammatory cytokines, in particular interleukin-6 (IL-6) [16-18]. Hepcidin is also produced by macrophages and neutrophils during the innate immune response through a Toll-like receptor 4-dependent pathway [19]. In contrast, the level of hepcidin decreases during hypoxia, during iron deficiency, and when erythropoietic needs are increased [5].

2.2. Iron and ROS. ROS possess paradoxical cellular effects, as they can both induce cell growth and survival or trigger cell death. Multiple factors influence the cellular effects of ROS, including ROS type as well as the level, localization, and duration of the assault [20-22]. Low levels of ROS act as second messengers in many important signaling pathways, while prolonged exposure to higher levels can exceed cellular antioxidant defenses and damage DNA, lipids, and proteins [21, 23]. A complex relationship exists between iron metabolism and oxidant status (Figures 1 and 2). Free iron plays an important role in ROS production as it can participate in the Fenton and Haber-Weiss reactions to yield superoxide anion and the highly reactive hydroxyl radical [20-22]. To prevent iron-catalyzed ROS production, iron levels are strictly regulated by multiple factors including hepcidin and FPN, as described above.

During inflammation, various pathways in immune cells are involved in the generation of ROS and RNS [24]. ROS and RNS generation can lead to significant tissue damage and is responsible for a variety of inflammatory disease processes [20-22]. Proinflammatory cytokines induced by inflammation can stimulate anemia of inflammation by limiting serum iron and increasing cellular iron stores by modulating the expression and activity of various iron regulatory proteins including hepcidin, FPN, ferritin, and the iron importer divalent metal transporter 1 (DMT1) [25-30]. Due to their role in iron recycling from erythrocytes, iron loading in macrophages is particularly significant [31]. Iron accumulation, in addition to increased levels of ROS and RNS induced by other facets of inflammation, may lead to increased labile iron, which can further perpetuate ROS production and damage through participation in the Fenton and Haber-Weiss reactions (Figure 2 ). In addition, increased labile iron can contribute to the activation of redox-sensitive transcription factors such as NF- $\kappa \mathrm{B}$, which is a potent regulator of inflammatory gene products including TNF- $\alpha$ [32]. An inhibitory effect on NF- $\kappa$ B-mediated generation of TNF- $\alpha$ and other inflammatory cytokines has been reported in Kupffer cells following the reduction of free iron by chelation [33].

\section{Iron Chelators}

3.1. Chemistry of Iron and Iron Chelators. ROS and RNS are produced both during normal aerobic respiration of cells and at increased rates and concentrations as part of the inflammatory response. Of the various reactive species, ROS have free iron directly involved in their production through the Fenton and Haber-Weiss reactions. Thus, the harnessed and controlled redox cycling of iron, which contributes 


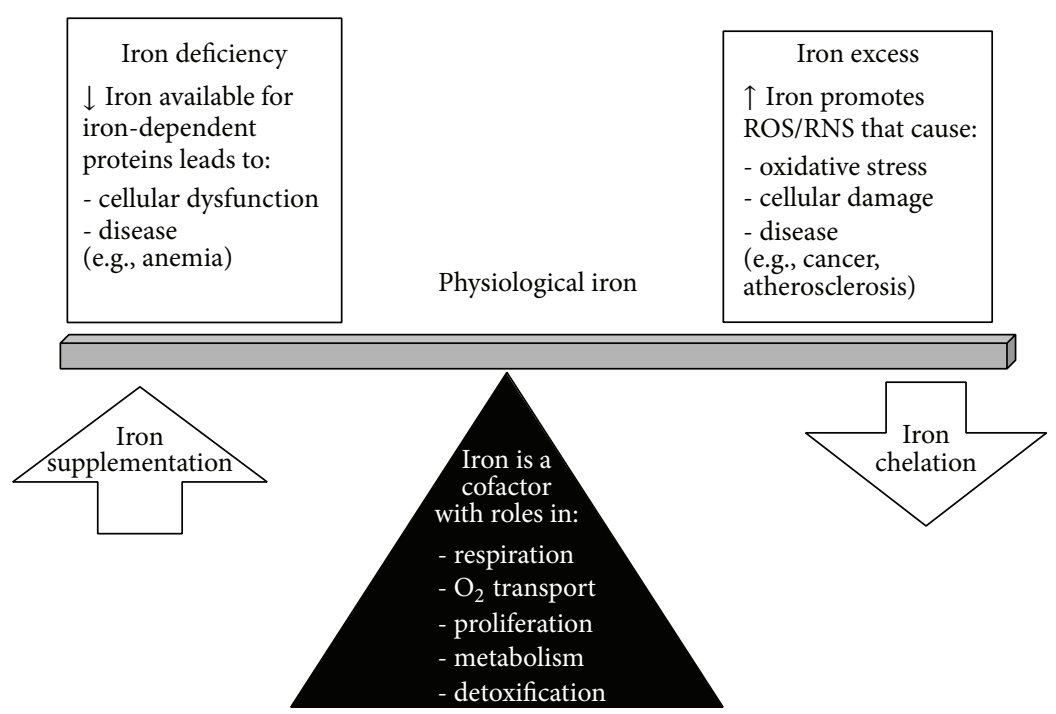

FIGURE 1: Role of iron in the development of disease.

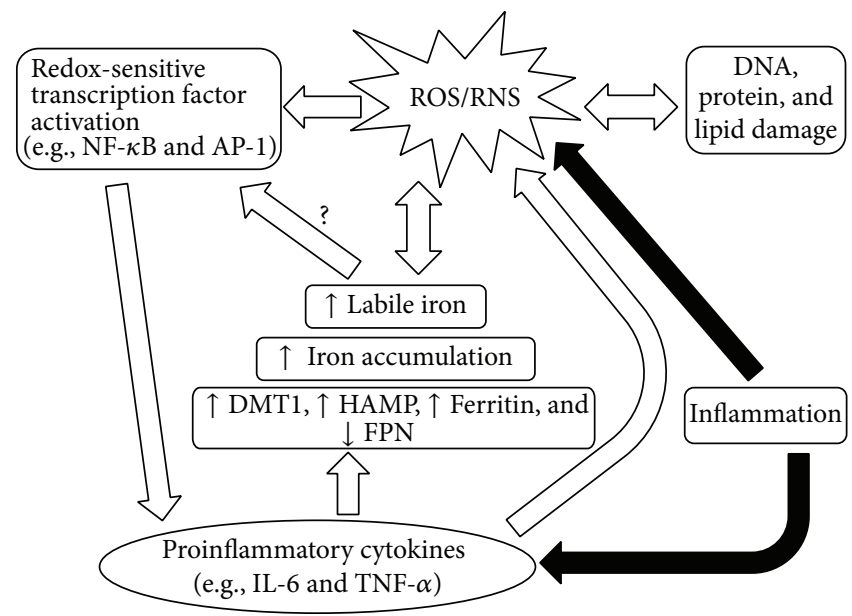

Figure 2: Putative involvement of iron in inflammation. Inflammation induces the production of proinflammatory cytokines which can induce the sequestration of iron within cells through the modulation of iron regulatory protein expression (e.g., divalent metal transporter 1 (DMT1), hepcidin (HAMP), ferritin, and ferroportin1 (FPN)). Increased iron levels, especially in macrophages, may lead to ROS production via the Fenton and Haber-Weiss reactions. ROS in return can increase levels of labile iron and induce oxidative damage of DNA, proteins, and lipids. Additionally, ROS can activate redox-sensitive transcription factors whose targets include proinflammatory cytokines.

activity for cell-essential iron-dependent enzymes such as the cytochromes, myeloperoxidase, or superoxide dismutase, also provides a less controlled source of cell-damaging reactive chemicals; that is, should free iron be available for Fenton or Haber-Weiss chemistry, the latter comprises essentially side reactions.

Iron can achieve hexadentate coordination with electrondonating ligands and when fully coordinated it is relatively redox stable. Studies have shown that Fenton-induced hydroxyl radical formation requires at least one free coordination site on the catalyzing iron [34]. Moreover, these studies were done using various chelating molecules with varying abilities to coordinate up to the six available coordination sites on iron and these therefore illustrated a key feature of iron chelators. For example, iron-EDTA and iron-bleomycin chelates are redox-active liberating radicals while the hexadentate Fe-desferal chelate is relatively redox-stable [34]. By definition (IUPAC, 1997) a metal chelate includes at least two coordinate bonds with a metal contributed by a chelating ligand and this, therefore, has important implications for the selection and use of iron chelators for treating inflammation or other disease conditions. It is interesting to note that the transferrins which are the main vertebrate iron chelator and transport protein molecules hold iron protected, within the transferrin structure itself, fully coordinating bound iron in a stable form using carbonate as a coligand [35]. Iron has a hexadentate coordination capacity. Noncoordinated sites have a high reactivity. Therefore, inappropriate or weak chelating molecules that retain their chelated iron with free, otherwise redox reactive coordination sites could be 
problematic as to undesirable radical generation. This issue might be further compounded on the basis that such chelators might solubilize and hold additional reactive iron spatially available at or near sensitive sites or, alternately, might deliver reactive iron to sensitive sites for participation in hydroxyl radical formation. An example of this problem is evident with the aminoglycoside antibiotics used to treat bacterial infection but known to possess ototoxicity related to oxidative radical formation when these agents bind iron in a redox active state [36].

\subsection{Anti-Inflammatory Chelators, Designer Molecules, and Other Pharmaceutical Agents as Iron Chelating Anti-Inflammatory Agents}

3.2.1. Natural Products. Desferal (Novartis), also known as desferrioxamine or deferoxamine $\mathrm{B}$, is a natural microbial product and an excellent example of a siderophore produced by microbes, in this case by Streptomyces spp. [37]. Both pathogenic bacteria [38] and fungi [39] can produce iron chelating siderophores as one strategy for obtaining host iron that is essential to their growth and pathogenesis [37, 39]. Iron withholding and microbial acquisition are key aspects of the host parasite battle during the pathogenesis of infection $[40,41]$. While desferrioxamine reduced experimental LPSinduced inflammation in mice, its use and that of other microbial chelators need to be carefully considered given that these agents could potentially promote infection owing to their microbial origin, for example, as has been shown for desferrioxamine with Yersinia enterocolitica [42] or Candida albicans [43].

A variety of natural phytochemicals have been described as having anti-inflammatory activity and some of these have been shown to possess iron-chelating activity [44]. For example, curcuminoids bind ferric iron in vitro and alleviate iron toxicity in thalassemic mice $[45,46]$. In addition, Aayush et al. [47] recently reviewed the iron chelating activity of African walnut and wheat grass extracts as to their potential for natural iron removal agents for iron overload associated with thalassemia, which is currently typically treated clinically with desferal. However, the role that iron chelation plays with various phytochemicals in relation to their anti-inflammatory activities remains unclear.

3.2.2. Synthetic Compounds. As to synthetic agents with antiinflammatory activity, ibuprofen, a widely used synthetic anti-inflammatory agent, has been shown to chelate iron in a stable form without a free Fenton-reactive coordination site and to protect from lipid peroxidation in vitro and phosgeneinduced septic lung injury in rabbits [48]. This evidence suggests at least part of ibuprofen's mode of action is related to iron chelation and suppression of ROS activity.

Research on newer generation synthetic iron chelators has produced a number of candidate molecules primarily in relation for their potential for treating iron overload or as anticancer agents. In this regard, agents that hold iron in a ROS-reactive manner have been reviewed, their enhanced ROS being proposed to provide killing of cancer cells [49]. Such ROS-reactive molecules would not likely provide anti-inflammatory activity but, conversely, could induce inflammatory responses.

On the other hand, new iron chelators that bind iron in a stable manner would be useful for treating iron overload diseases and thus, presumably, inflammation. Kalinowski and Richardson have recently reviewed synthetic chelators based on various chelating chemical groupings such as catechol, hydroxamate, and hydroxypyridinone, concluding that structures providing hexadentate hydroxypyridinone functionality (an example being deferiprone) have particular promise as bacteriostatic agents in relation to outcompeting siderophores of microbes [49]. However, the hydroxamate desferal and the hydroxypyridinone deferiprone have been shown to be accessible by various micoorganisms thereby restricting their potential use as microbial control agents [50]. Holbein and Mira reported that DIBI, a new chelator, which possesses modified hydroxypyridinone activity, provided Fe-specific growth inhibition of Candida albicans [43]. DIBI is one example of a new approach to providing controlled molecular weight chelating-functional polymers. These agents may provide an additional advantage through providing compartmentalized sinks for iron thus reducing its participation in ROS inflammatory reactions or its bioavailability to either pathogenic cancer or microbial cells.

\section{Experimental Studies}

4.1. Cancer. Deficient regulation of iron homeostasis can contribute to tumor development through a number of different mechanisms (Figure 1, Table 1). The iron-catalyzed production of ROS and subsequent damage to DNA can result in the loss of tumor suppressors and activation of oncogenes $[51,52]$. Oxidative stress may also modulate signal transduction pathways associated with malignancy [53]. Cancer cells require considerably more iron than normal cells due to their increased rate of DNA synthesis and utilization of the iron-dependent enzyme ribonucleotide reductase [54]. Thus, cancer cells have increased expression of transferrin receptor-1 and a higher rate of iron uptake from transferrin $[55,56]$, as well as decreased expression of iron exporters [57]. In addition, iron regulates the activity of the transcription factors NF- $\kappa \mathrm{B}$ and HIF- $1 \alpha$ [58], which promote the expression of genes involved in the survival and metastasis of cancer cells $[59,60]$. Interestingly, higher concentrations of free iron in breast cancer cells are associated with a more aggressive tumor phenotype [57]. It follows that cancer cells are more sensitive to iron deprivation than normal cells and may therefore be susceptible to treatment with iron chelators [61].

4.2. Atherosclerosis. Atherosclerosis is characterized by chronic vascular inflammation [74]. It has been suggested that the development of atherosclerosis is associated with the amount of iron stored in the body and iron may contribute to the pathogenesis of atherosclerosis by acting as a regulator of vascular oxidative stress and inflammatory immune responses in atherosclerosis [75]. Increased levels of iron and oxidized lipids are both found in high-cholesterol diet-fed rabbits associated with atherosclerotic lesions [62]. Iron chelation by deferoxamine reduced the expression of oxidative 
TABLE 1: Selected experimental studies.

\begin{tabular}{|c|c|c|c|}
\hline Disease & Subject & Results & Reference \\
\hline \multirow[b]{2}{*}{ Cancer } & $\begin{array}{l}\text { Analysis of the specific murine } \\
\text { OKT9-antibody on human leukemia cells }\end{array}$ & $\begin{array}{l}\text { OKT9 receptor is transferrin } \\
\text { OKT9 binding on both normal and malignant } \\
\text { cells was strongly associated with proliferation }\end{array}$ & {$[55]$} \\
\hline & $\begin{array}{l}\text { Expression of ferroportin and hepcidin in } \\
\text { cultured human breast cancer cells plus an } \\
\text { observational cohort study in patients }\end{array}$ & $\begin{array}{l}\text { Reduction of ferroportin in cancer cells altered } \\
\text { the labile iron pool } \\
\text { Combined ferroportin/hepcidin gene expression } \\
\text { identified clinical subset of breast cancer }\end{array}$ & {$[58]$} \\
\hline \multirow{3}{*}{ Atherosclerosis } & $\begin{array}{l}\text { Influence of zinc to the development of } \\
\text { atherosclerotic plaques }\end{array}$ & $\begin{array}{l}\text { Zinc fed rabbits showed decreased atherosclerotic } \\
\text { plaques } \\
\text { Average lesion Fe levels in the zinc-fed group were } \\
\text { significantly higher }\end{array}$ & {$[62]$} \\
\hline & $\begin{array}{l}\text { Effect of iron chelation on ferritin induction } \\
\text { and iron accumulation in the rat aorta } \\
\text { depending on Angiotensin II administration } \\
\text { and vascular function }\end{array}$ & $\begin{array}{l}\text { Angiotensin II infusion caused ferritin induction } \\
\text { and iron deposition in the aortas } \\
\text { Impairment of vascular function was mediated in } \\
\text { part by enhancement of oxidative stress }\end{array}$ & {$[63]$} \\
\hline & $\begin{array}{l}\text { Relationship between chronic } \\
\text { hemolysis/increased body iron burden and } \\
\text { premature atherosclerosis }\end{array}$ & $\begin{array}{l}\text { Carotid intima-media thickness in patients with } \\
\text { thalassemia major was significantly increased } \\
\text { compared with healthy controls }\end{array}$ & {$[64]$} \\
\hline \multirow[t]{2}{*}{ Diabetes and Obesity } & $\begin{array}{l}\text { Role of iron in adiposity using diabetic and } \\
\text { obese mice model (KKAy) DFO treatment }\end{array}$ & $\begin{array}{l}\text { DFO diminished fat iron and serum ferritin } \\
\text { levels, reduced fat weight and adipocyte size, and } \\
\text { reduced macrophage infiltration, superoxide } \\
\text { production, NADPH oxidase activity, and mRNA } \\
\text { of inflammatory cytokines }\end{array}$ & {$[65]$} \\
\hline & $\begin{array}{l}\text { Effect of intravenous iron preparation on the } \\
\text { beta cells in isolated pancreatic islets }\end{array}$ & $\begin{array}{l}\text { Exposure to iron resulted in a } \\
\text { concentration-dependent oxidative stress and } \\
\text { pancreatic islet cell death predominantly affecting } \\
\text { beta cells }\end{array}$ & {$[66]$} \\
\hline Renal fibrosis & $\begin{array}{l}\text { Effect of an iron chelator (DFO) on renal } \\
\text { fibrosis induced by unilateral ureteral } \\
\text { obstruction in mice }\end{array}$ & $\begin{array}{l}\text { DFO suppressed changes including macrophage } \\
\text { infiltration, expression of collagen and } \\
\text { inflammatory cytokines, activation of the } \\
\text { TGF-betal/Smad3 pathway, and tubulointerstitial } \\
\text { fibrosis }\end{array}$ & {$[67]$} \\
\hline \multirow{2}{*}{ Glaucoma } & $\begin{array}{l}\text { To investigate the association between } \\
\text { dietary and total calcium and iron } \\
\text { consumption with a diagnosis of glaucoma }\end{array}$ & $\begin{array}{l}\text { Odds of glaucoma were increased in the } \\
\text { population with higher total consumption of } \\
\text { calcium and iron }\end{array}$ & {$[68]$} \\
\hline & $\begin{array}{l}\text { To study the effect of metal chelator EDTA } \\
\text { on the rat optic nerve and retinal ganglion } \\
\text { cells exposed to oxidative stress }\end{array}$ & $\begin{array}{l}\text { EDTA ameliorated oxidative damage and } \\
\text { inflammation, increased survival of retinal } \\
\text { ganglion cell, and decreased demyelination of } \\
\text { optic nerve }\end{array}$ & {$[69]$} \\
\hline \multirow{3}{*}{$\begin{array}{l}\text { Systemic inflammatory } \\
\text { response syndrome }\end{array}$} & $\begin{array}{l}\text { To study the effect of DFO on acute hepatic } \\
\text { ischemia induced SIRS in pigs }\end{array}$ & $\begin{array}{l}\text { DFO completely blocked IL- } 6 \text { production and } \\
\text { lipid peroxidation and attenuated the } \\
\text { development of SIRS and MOD }\end{array}$ & {$[70]$} \\
\hline & $\begin{array}{l}\text { To study the effect of DFO on acute hepatic } \\
\text { ischemia induced SIRS in swine }\end{array}$ & $\begin{array}{l}\text { DFO inhibited iron-catalyzed oxidative reactions, } \\
\text { delayed the development of intracranial } \\
\text { hypertension, and improved survival }\end{array}$ & {$[71]$} \\
\hline & $\begin{array}{l}\text { To test the hypothesis that inhibition of } \\
\text { oxidative stress through iron chelation with } \\
\text { DFO attenuates pulmonary injury caused by } \\
\text { acute liver failure (ALF) }\end{array}$ & $\begin{array}{l}\text { DFO reduced systemic and pulmonary oxidative } \\
\text { stress during ALF, attenuated pneumonocyte } \\
\text { necrosis, improved alveolocapillary membrane } \\
\text { permeability, and prevented alveolar space } \\
\text { collapse }\end{array}$ & {$[72]$} \\
\hline Colitis & $\begin{array}{l}\text { To evaluate the effect of selected iron } \\
\text { chelators and antioxidants on protection of } \\
\text { trinitrobenzene sulfonic acid (TNBS) } \\
\text { induced colitis in rats }\end{array}$ & $\begin{array}{l}\text { Maltol (iron chelator) was capable of protecting } \\
\text { rat from TNBS induced colitis. Kojic acid (iron } \\
\text { chelator) and vitamin E (antioxidant) were not } \\
\text { effective }\end{array}$ & {$[73]$} \\
\hline
\end{tabular}


stress markers and delayed the formation of atherosclerotic lesions, indicating that chelation therapy may aid in prevention of atherosclerosis $[63,76]$.

4.3. Diabetes and Obesity. Diabetes mellitus is characterized by an impaired glucose metabolism with the main symptom of hyperglycemia, caused either by impaired insulin secretion or impaired insulin action or both [77]. Obesity is characterized by an increase in the number and/or the size of the fat cells [78]. By activating adipocytes and stimulating their growth, iron contributes to obesity. Iron reduction by deferoxamine resulted in amelioration of adiposity via the regulation of oxidative stress and inflammation in obese and type 2 diabetes mice [65]. Interestingly, despite of deferoxamine administration for two weeks, there was only a mild but not significant reduction in the haemoglobin concentration and the hematocrit between vehicle-treated and chelatortreated mice (Table 1).

The uptake of unbound, that is, non-transferrin-bound iron, into pancreatic beta cells causes oxidative stress via the Fenton reaction. Due to their reduced antioxidant capacity, cell death is induced in the beta cells of isolated pancreatic islets by pharmacological-relevant iron concentrations that may occur during intravenous iron supplementation [66].

4.4. Renal Fibrosis. Renal interstitial fibrosis is characterized by the accumulation of collagen and related molecules in the interstitium, involving cells like tubular epithelial cells, fibroblasts, fibrocytes, myofibroblasts, monocyte/macrophages, and mast cells [79], and can be caused inter alia by inflammatory processes [80]. In a recent study, the impact of deferoxamine on experimentally induced renal fibrosis was explored, again with an emphasis on inflammation caused by iron induced oxidative stress. After a surgically induced unilateral ureter obstruction (UUO), mice treated with DFO showed significantly less fibrotic progression, less interstitial macrophage infiltration, and thereby a reduced expression of IL-1 $\beta$ and MCP-1 and a suppressed UUO-induced accumulation of myofibroblasts, compared with untreated mice. The authors concluded that in mice iron reduction by deferoxamine may prevent renal interstitial fibrosis by regulating TGF-beta/Smad signaling, oxidative stress, and inflammatory responses [67].

4.5. Glaucoma. Elevated intraocular pressure, the main risk factor for glaucoma, triggers the initiation and progression of oxidative stress-induced cell damage [81]. The disease is marked by loss of optic nerve axons and retinal ganglion cells, resulting in characteristic optic nerve atrophy and visual field defects [69]. Wang et al. observed a correlation of iron intake and the odds of glaucoma in humans [68].

In an in vivo model in rats, chelation treatment ameliorated ocular sequelae caused by increased intraocular pressure. The topically administered metal chelator, EDTA, combined with a permeability enhancer reduced signs of oxidative stress and inflammation in glaucoma in the rat's eyes, increased retinal ganglion cell survival, and decreased demyelination of optic nerve compared with untreated eyes [69].

4.6. Systemic Inflammatory Response Syndrome. Systemic inflammatory response syndrome (SIRS) is characterized by specific physiological alterations, including temperature, white blood cell count, heart rate, and respiratory rate, caused by a broad spectrum of noninfectious and infectious triggers [82]. Hypoferremia in SIRS is observed in humans [83] and animals $[84,85]$. In acute hepatic ischemia induced SIRS and consecutive multiple organ dysfunction (MOD) in pigs, Vlahakos et al. [70] demonstrated that DFO attenuated lipid peroxidation, inhibited IL-6 production, and substantially diminished SIRS and MOD. Tubulointerstitial damage in the porcine kidney as expression of severity of SIRS induced organ failure was reduced by a bolus followed by a continuous infusion of the chelator. These results suggest that iron plays a pivotal role in the pathogenesis of SIRS and MOD including acute kidney injury by its involvement in various inflammatory pathways and in the generation of reactive oxygen species. Using the same model, the researchers also demonstrated that application of DFO significantly reduced brain edema, intracranial pressure, and lung injury $[71,72]$.

In an endotoxemic mouse model, lactoferrin, a nonheme iron-binding glycoprotein, decreased LPS-induced oxidative burst and reactive oxygen species in cultured cells and attenuated mitochondrial dysfunction in liver of endotoxemic mice [86]. In a carbon tetrachloride induced acute hepatic injury rat model, application of DFO significantly decreased oxidative stress and limited inflammatory infiltration and hepatocyte necrosis, resulting in reduced mortality rate [87].

4.7. Ischemia Reperfusion Injury. Ischemia reperfusion injury can be regarded as the most exaggerated form of oxidative stress for cells [88]. $\mathrm{ONOO}^{-}$and $\mathrm{H}_{2} \mathrm{O}_{2}$ produced in the reperfusion phase are known to release iron ions from intracellular iron-sulphur proteins thus increasing intracellular labile iron pool, which in turn promotes by the above-outlined reactions the production of further reactive species [89].

In the postischemic renal injury model in rats, acute iron loading exacerbated postischemic lipid peroxidation and renal injury, while reducing iron level by DFO suppressed lipid peroxidation and improved renal function [90]. In a cardioplegia-ischemia and reperfusion model via cardiopulmonary bypass in sheep, DFO protected lung injury by inhibiting endothelial injury and eliminating postischemic cardiac stunning [91].

4.8. Colitis. Colitis is another example for chronic inflammation, leading to anemia of inflammation as a consequence of low serum iron and low iron-binding capacity [92].

Using a trinitrobenzene sulfonic acid induced colitis rat model, Minaiyan and coworkers compared the effect of deferiprone and deferoxamine with the newer iron chelators, maltol and kojic acid, on inflammatory response. In the highest dosage maltol was comparable with prednisolone as 
standard anti-inflammatory drug and also deferoxamine and deferiprone as reference iron binding agents [73].

\section{Clinical Evidence}

\subsection{Iron Homoeostasis in Inflammation}

5.1.1. Anemia of Inflammation. Anemia represents a common clinical finding in patients with acute or chronic inflammation. In acute inflammation (e.g., trauma and surgery) the two major mechanisms leading to anemia are blood loss and blunted erythropoiesis due to decreased iron availability $[93,94]$. In the event of chronic blood loss and/or persisting decreased iron absorption, acute anemia may evolve to anemia of chronic disease (ACD) with true iron deficiency (ACD+ID).

Anemia in chronic inflammation (without blood loss or decreased baseline iron availability) represents a specific entity, that is, ACD. It is observed, for example, in cancer, rheumatoid arthritis, inflammatory bowel diseases, and congestive heart failure, as well as in sepsis and chronic renal failure. This anemia is the result of activation of the immune system by the underlying process and certain immune and inflammatory cytokines including tumor necrosis factor-alpha, interferon-gamma, IL-1, IL-6, IL-8, and IL-10 [4, 95].

5.1.2. Hepcidin. The discovery of hepcidin yielded significant insight into the link between the immune response in inflammation and systemic iron homoeostasis. The abovementioned cytokines are known to increase hepcidin expression. Circulating hepcidin expression in vivo has also been correlated with acute phase proteins such as C-reactive protein, $\alpha$-1-acid-glycoprotein, ferritin, and amyloid A [96, 97].

Hepcidin produced by the hepatocytes binds to its receptor FPN, which is an iron export protein that is present on limited cells such as macrophages, hepatocytes, duodenal enterocytes, and placental syncytiotrophoblasts [98]. Hepcidin binding to ferroportin leads to ubiquitinization, followed by internalization and degradation of FPN [98]. The end result is that iron cannot be released into the plasma and remains trapped inside the macrophages and hepatocytes, resulting in an increase in iron stores reflected in high levels of serum ferritin [29]. In addition, hepcidin inhibits intestinal absorption of iron [99]. Therefore, ACD is characterized by low serum iron, transferrin, and total iron binding capacity, by normal transferrin saturation, and by increased ferritin, the latter in contrast to iron deficiency anemia. The low transferrin levels are due to downregulation of transferrin synthesis as a result of an increase in ferritin.

The increase in hepcidin production in response to inflammation is a protective mechanism in the case of infections in which iron restriction would limit bacterial growth. However, in ACD or inflammation without infection, this mechanism can have detrimental consequences when iron remains sequestered in the macrophages and hepatocytes and is not available for erythropoiesis, resulting in anemia [97].

\subsection{Preexisting Diseases with Iron Overload}

5.2.1. Hereditary Iron Storage Diseases. Iron overload can be the result of hereditary (primary) or acquired (secondary) increase in iron storage. The most common hereditary iron storage disease is hemochromatosis. Most forms of hemochromatosis result from dysregulation of hepcidin or defects of hepcidin or ferroportin themselves [100]. When hepcidin binds to ferroportin it causes internalization of ferroportin and its proteolytic destruction [17]. Thus, hepcidin serves to prevent the egress of iron both from intestinal cells and from macrophages. Hepcidin is normally upregulated by excess iron stores [17]. This serves to prevent further absorption of iron from the gastrointestinal tract and its release from macrophages. It is this regulation that is impaired in several types of hemochromatosis [100]. There is evidence that patients with hemochromatosis have a higher risk for infectious diseases. Iron overload associated with hereditary hemochromatosis has been reported to confer susceptibility to infectious pathogens, such as Yersinia enterocolitica and Vibrio vulnificus [101].

5.2.2. Acquired Iron Storage Disease. Acquired iron overload is frequently observed in thalassemia, myelodysplastic syndromes, congenital dyserythropoietic anemias, sickle cell disease, and other hemoglobinopathies. Patients with thalassemia, whose erythroid precursor populations are greatly expanded but fail to mature into functional erythrocytes, have increased intestinal iron absorption despite often severe systemic iron overload [102]. Although blood transfusions given for severe anemia (e.g., thalassemia major) contribute to the lethal iron overload in ineffective erythropoiesis, many patients with less severe anemia (e.g., thalassemia intermedia) receive few or no transfusions but still become severely iron-overloaded [103]. Walter et al. found increased levels of plasma malondialdehyde in thalassemia [104]. They described three potential mechanisms: (i) the excess $\alpha$-chains in $\beta$-thalassemic erythrocytes and erythroblasts being unstable and prone to denaturation and oxidation, (ii) peroxidation of tissues that leak malondialdehyde into the blood, and (iii) depleted antioxidant capacity lowering defense against oxidants [105]. Infections and inflammations are more frequent in thalassemic patients with iron overload induced by frequent blood transfusions [104].

5.2.3. Other Diseases with Iron Involvement. Iron accumulation and increased oxidative stress were also described in the pathogenesis of preeclampsia [2], diabetes [106], the metabolic syndrome [107], obesity [108], hypertension [109], cardiovascular diseases [110], heart failure [95], atherosclerosis [111], stroke [112], Alzheimer's, Parkinson's and other major neurodegenerative diseases [113], Friedreich's ataxia [114], amyotrophic lateral sclerosis [115], rheumatoid arthritis [116], systemic lupus erythematosus [117], asthma [118], inflammatory bowel diseases [119], age-related macula degeneration [120], psoriasis [121], gout [122], chronic obstructive pulmonary disorder [123], cancer [51], malaria [124], and other diseases (for overviews see Kell 2009 [2] and Weinberg $2010[125])$. 
5.3. Preexisting Diseases with Iron Deficiency. Iron deficiency (ID) can be caused by inadequate oral iron uptake (dietary), inadequate iron absorption (e.g., celiac disease), excessive blood loss, or increased iron demand (e.g. growth or pregnancy). The clinical picture of ID patients is usually characterized by mild to severe anemias and further consequences, including epithelial changes (stomatitis and glossitis), and neurocognitive effects, that is, impaired motor and mental functioning [126]. Imperative to treatment is identifying the underlying cause of iron deficiency. Oral iron replacement is preferentially used to replete iron stores. Ferrous sulfate is the most common oral iron supplement used [126].

However, in the same way that primary or secondary iron storage diseases can cause oxidative stress, artificial iron overload due to therapeutic administration can cause harm for the patients. The Pemba trial, which led to adverse events in children receiving iron in a malaria-endemic region, underscores the need for caution [127]. For tuberculosis, it has been demonstrated that parenteral or oral iron increase mycobacterial growth [128] and that morbidity and mortality increase in patients receiving iron supplementation [129]. In fact, dietary iron is associated with occurrence and death from tuberculosis [130].

Mild ID has been associated with protection against certain inflammatory and infectious conditions. The "iron hypothesis" of the benefits of some iron depletion due to menstruation was devised to account for the lowering of heart-disease risk in young women that disappears in those who are postmenopausal $[131,132]$.

\subsection{Clinical Iron Removal in Inflammation}

5.4.1. Potential Indications. Depending on the localization and severity of the inflammatory condition, different approaches and routes of administration for iron chelators are feasible. The route of administration as well as needs for extraand/or intracellular action determines the required molecular structure and weight of the iron chelating substances. For wound infections, topical/local administration of large molecular size substances might be feasible, whereas for systemic (SC/IV/IP) administration (e.g., sepsis) smaller molecules might be necessary. Due to the bacteriostatic/bactericidal effects of iron removal from media, the use of iron chelators as preservatives in standard medications (e.g., eye drops) is also an option. In the same way, application of iron chelators as adjunct to peritoneal lavage fluids appears to be an option for both prophylactic and therapeutic purposes.

5.4.2. Potential Limitations. Suggesting that inflammatory disorders might be treatable by the induction of a second disorder, that is, iron depletion, might be seen as a controversial proposal due to the prevalent assumption that iron in storage is inherently safe. This assumption is based on traditional medical practices rather than on rigorous clinical trials [133]. It has been previously stated that the benefit of iron depletion can only be rigorously demonstrated in relation to the state of iron in excess of needs (i.e., the condition of having iron in storage). It has not been widely appreciated that the safety of stored iron can only be shown with clarity in studies of the same design. Absence of proof that iron depletion is beneficial implies an absence of proof of the safety of stored iron. Because of the deeply rooted assumption that stored iron is safe, appropriate trials to rule out the potential hazards of iron stores have not been undertaken [134]. But even if there exists a potential (short-term) harm of iron depletion (e.g., anemia) when administered in inflammatory diseases, this can be compared with "side effects" of chemotherapy in cancer: "collateral damage" appears acceptable, if it is possible to get control over the main, potentially life-threatening condition.

\section{Conclusions}

Iron is involved in almost every clinical condition of acute or chronic inflammation. Since iron can contribute to detrimental ROS and RNS generating processes, it seems to be a reasonable approach to modulate iron-related pathways in inflammation. In humans (with normal baseline iron levels), a counterregulatory reduction in iron availability is observed during inflammatory diseases (anemia of inflammation). Under pathological conditions with reduced or increased baseline iron levels different consequences regarding protection or susceptibility to inflammation have to be considered.

Therapeutic interventions with iron or iron chelators have an impact on the oxidant status and iron chelation might be utilized as a potential antioxidative strategy in inflammatory diseases. New iron chelators designed to sequester iron in a nonredox active state may prove to provide increased efficacy in this regard. Additional requirements for new iron chelators apply in infection-induced, local, and systemic inflammation. Conventional clinical chelators do not effectively deny iron to pathogens; in fact pathogens can utilize these conventional chelators as iron sources. This underscores the need for superior chelators since agents like desferal or deferiprone as antimicrobials agents have provided varying results depending on the microbe being tested.

\section{Conflict of Interests}

The authors declare that there is no conflict of interests regarding the publishing of this paper.

\section{References}

[1] M. Wessling-Resnick, "Iron homeostasis and the inflammatory response," Annual Review of Nutrition, vol. 30, pp. 105-122, 2010.

[2] D. B. Kell, "Iron behaving badly: Inappropriate iron chelation as a major contributor to the aetiology of vascular and other progressive inflammatory and degenerative diseases," BMC Medical Genomics, vol. 2, article 2, 2009.

[3] M. Nairz, D. Haschka, E. Demetz, and G. Weiss, "Iron at the interface of immunity and infection," Frontiers in Pharmacology, vol. 5, pp. 1-10, 2014.

[4] G. E. Cartwright, M. A. Lauritsen, S. Humphreys, P. J. Jones, I. M. Merrill, and M. M. Wintrobe, "The anemia associated with chronic infection," Science, vol. 103, no. 2664, pp. 72-73, 1946.

[5] B. K. Fuqua, C. D. Vulpe, and G. J. Anderson, "Intestinal iron absorption," Journal of Trace Elements in Medicine and Biology, vol. 26, no. 2-3, pp. 115-119, 2012. 
[6] M. Domellöf, I. Thorsdottir, and K. Thorstensen, "Health effects of different dietary iron intakes: a systematic literature review for the 5th Nordic Nutrition Recommendations," Food \& Nutrition Research, p. 57, 2013.

[7] G. Weiss, "Iron metabolism in the anemia of chronic disease," Biochimica et Biophysica Acta, vol. 1790, no. 7, pp. 682-693, 2009.

[8] S. Waldvogel-Abramowski, G. Waeber, C. Gassner et al., "Physiology of iron metabolism," Transfusion Medicine and Hemotherapy, vol. 41, no. 3, pp. 213-221, 2014.

[9] D. M. Frazer and G. J. Anderson, "The regulation of iron transport," BioFactors, vol. 40, no. 2, pp. 206-214, 2014.

[10] P. A. Sharp, "Intestinal iron absorption: regulation by dietary \& systemic factors," International Journal for Vitamin and Nutrition Research, vol. 80, no. 4-5, pp. 231-242, 2010.

[11] Z. Cheng and Y. Li, "What is responsible for the initiating chemistry of iron-mediated lipid peroxidation: an update," Chemical Reviews, vol. 107, no. 3, pp. 748-766, 2007.

[12] E. Nemeth and T. Ganz, "The role of hepcidin in iron metabolism," Acta Haematologica, vol. 122, no. 2-3, pp. 78-86, 2009.

[13] M. D. Knutson, "Iron-sensing proteins that regulate hepcidin and enteric iron absorption," Annual Review of Nutrition, vol. 30, pp. 149-171, 2010.

[14] I. de Domenico, D. M. Ward, and J. Kaplan, "Hepcidin and ferroportin: the new players in iron metabolism," Seminars in Liver Disease, vol. 31, no. 3, pp. 272-279, 2011.

[15] L. Mercadel, M. Metzger, J. P. Haymann et al., "The relation of hepcidin to iron disorders, inflammation and hemoglobin in chronic kidney disease," PLoS ONE, vol. 9, Article ID e99781, 2014.

[16] V. Dzikaite, P. Holmström, P. Stål et al., "Regulatory effects of tumor necrosis factor-alpha and interleukin-6 on HAMP expression in iron loaded rat hepatocytes," Journal of Hepatology, vol. 44, no. 3, pp. 544-551, 2006.

[17] E. Nemeth, M. S. Tuttle, J. Powelson et al., "Hepcidin regulates cellular iron efflux by binding to ferroportin and inducing its internalization," Science, vol. 306, no. 5704, pp. 2090-2093, 2004.

[18] E. Nemeth, E. V. Valore, M. Territo, G. Schiller, A. Lichtenstein, and T. Ganz, "Hepcidin, a putative mediator of anemia of inflammation, is a type II acute-phase protein," Blood, vol. 101, no. 7, pp. 2461-2463, 2003.

[19] C. Peyssonnaux, A. S. Zinkernagel, V. Datta, X. Lauth, R. S. Johnson, and V. Nizet, "TLR4-dependent hepcidin expression by myeloid cells in response to bacterial pathogens," Blood, vol. 107, no. 9, pp. 3727-3732, 2006.

[20] E. Panieri, V. Gogvadze, E. Norberg, R. Venkatesh, S. Orrenius, and B. Zhivotovsky, "Reactive oxygen species generated in different compartments induce cell death, survival, or senescence," Free Radical Biology and Medicine, vol. 57, pp. 176-187, 2013.

[21] M. Valko, D. Leibfritz, J. Moncol, M. T. D. Cronin, M. Mazur, and J. Telser, "Free radicals and antioxidants in normal physiological functions and human disease," International Journal of Biochemistry and Cell Biology, vol. 39, no. 1, pp. 44-84, 2007.

[22] T. Kietzmann, "Intracellular redox compartments: mechanisms and significances," Antioxidants and Redox Signaling, vol. 13, no. 4, pp. 395-398, 2010.

[23] N. K. Tonks, "Redox redux: revisiting PTPs and the control of cell signaling," Cell, vol. 121, no. 5, pp. 667-670, 2005.

[24] P. C. Dedon and S. R. Tannenbaum, "Reactive nitrogen species in the chemical biology of inflammation," Archives of Biochemistry and Biophysics, vol. 423, no. 1, pp. 12-22, 2004.
[25] E. Nemeth, S. Rivera, V. Gabayan et al., "IL-6 mediates hypoferremia of inflammation by inducing the synthesis of the iron regulatory hormone hepcidin," Journal of Clinical Investigation, vol. 113, no. 9, pp. 1271-1276, 2004.

[26] D. M. Wrighting and N. C. Andrews, "Interleukin-6 induces hepcidin expression through STAT3," Blood, vol. 108, no. 9, pp. 3204-3209, 2006.

[27] J. Wang, N. Song, H. Jiang, and J. Xie, "Pro-inflammatory cytokines modulate iron regulatory protein 1 expression and iron transportation through reactive oxygen/nitrogen species production in ventral mesencephalic neurons," Biochimica et Biophysica Acta-Molecular Basis of Disease, vol. 1832, no. 5, pp. 618-625, 2013.

[28] P. Urrutia, P. Aguirre, A. Esparza et al., "Inflammation alters the expression of DMT1, FPN1 and hepcidin, and it causes iron accumulation in central nervous system cells," Journal of Neurochemistry, vol. 126, no. 4, pp. 541-549, 2013.

[29] S. Rivera, L. Liu, E. Nemeth, V. Gabayan, O. E. Sorensen, and T. Ganz, "Hepcidin excess induces the sequestration of iron and exacerbates tumor-associated anemia," Blood, vol. 105, no. 4, pp. 1797-1802, 2005.

[30] S. H. Atkinson, K. A. Rockett, G. Morgan et al., "Tumor necrosis factor SNP haplotypes are associated with iron deficiency anemia inWest African children," Blood, vol. 112, no. 10, pp. 4276-4283, 2008.

[31] N. C. Andrews and P. J. Schmidt, "Iron homeostasis," Annual Review of Physiology, vol. 69, pp. 69-85, 2007.

[32] S. Xiong, H. She, C. K. Sung, and H. Tsukamoto, "Iron-dependent activation of NF- $\kappa \mathrm{B}$ in Kupffer cells: a priming mechanism for alcoholic liver disease," Alcohol, vol. 30, no. 2, pp. 107-113, 2003.

[33] H. She, S. Xiong, M. Lin, E. Zandi, C. Giulivi, and H. Tsukamoto, "Iron activates NF- $\kappa \mathrm{B}$ in Kupffer cells," The American Journal of Physiology-Gastrointestinal and Liver Physiology, vol. 283, no. 3, pp. G719-G726, 2002.

[34] E. Graf, J. R. Mahoney, R. G. Bryant, and J. W. Eaton, "Ironcatalyzed hydroxyl radical formation: dtringent requirement for free iron coordination site," The Journal of Biological Chemistry, vol. 259, no. 6, pp. 3620-3624, 1984.

[35] P. Aisen, C. Enns, and M. Wessling-Resnick, "Chemistry and biology of eukaryotic iron metabolism," International Journal of Biochemistry and Cell Biology, vol. 33, no. 10, pp. 940-959, 2001.

[36] G. Perletti, A. Vral, M. C. Patrosso et al., "Prevention and modulation of aminoglycoside ototoxicity (Review)," Molecular Medicine Reports, vol. 1, no. 1, pp. 3-13, 2008.

[37] M. Imbert, M. Bechet, and R. Blondeau, "Comparison of the main siderophores produced by some species of Streptomyces," Current Microbiology, vol. 31, no. 2, pp. 129-133, 1995.

[38] C. Ratledge and L. G. Dover, "Iron metabolism in pathogenic bacteria," Annual Review of Microbiology, vol. 54, pp. 881-941, 2000.

[39] D. H. Howard, "Acquisition, transport, and storage of iron by pathogenic fungi," Clinical Microbiology Reviews, vol. 12, no. 3, pp. 394-404, 1999.

[40] E. P. Skaar, "The battle for iron between bacterial pathogens and their vertebrate hosts," PLoS Pathogens, vol. 6, no. 8, Article ID e1000949, 2010.

[41] J. W. Kronstad and M. Caza, "Shared and distinct mechanisms of iron acquisition by bacterial and fungal pathogens of humans," Frontiers in Cellular and Infection Microbiology, vol. 4, article 80, 2013. 
[42] R. M. Robins-Browne and J. K. Prpic, "Effects of iron and desferrioxamine on infections with Yersinia enterocolitica," Infection and Immunity, vol. 47, no. 3, pp. 774-779, 1985.

[43] B. E. Holbein and R. Mira de Orduña, "Effect of trace iron levels and iron withdrawal by chelation on the growth of Candida albicans and Candida vini," FEMS Microbiology Letters, vol. 307, no. 1, pp. 19-24, 2010.

[44] M. G. Miguel, "Antioxidant and anti-inflammatory activities of essential oils: a short review," Molecules, vol. 15, no. 12, pp. 92529287, 2010.

[45] S. Srichairatanakool, C. Thephinlap, C. Phisalaphong, J. B. Porter, and S. Fucharoen, "Curcumin contributes to in vitro removal of non-transferrin bound iron by deferiprone and desferrioxamine in thalassemic plasma," Medicinal Chemistry, vol. 3, no. 5, pp. 469-474, 2007.

[46] C. Thephinlap, C. Phisalaphong, S. Fucharoen, J. B. Porter, and S. Srichairatanakool, "Efficacy of curcuminoids in alleviation of iron overload and lipid peroxidation in thalassemic mice," Medicinal Chemistry, vol. 5, no. 5, pp. 474-482, 2009.

[47] K. Aayush, N. Wadhwa, and A. Tiwari, "Therapeutic role of natural agents in beta-thalassemia: a review," Journal of Pharmacy Research, vol. 6, pp. 954-959, 2013.

[48] T. P. Kennedy, N. V. Rao, W. Noah et al., "Ibuprofen prevents oxidant lung injury and in vitro lipid peroxidation by chelating iron," Journal of Clinical Investigation, vol. 86, no. 5, pp. 15651573, 1990.

[49] D. S. Kalinowski and D. R. Richardson, "Future of toxicologyiron chelators and differing modes of action and toxicity: the changing face of iron chelation therapy," Chemical Research in Toxicology, vol. 20, no. 5, pp. 715-720, 2007.

[50] M. G. Thompson, B. W. Corey, Y. Si, D. W. Craft, and D. V. Zurawski, "Antibacterial activities of iron chelators against common nosocomial pathogens," Antimicrobial Agents and Chemotherapy, vol. 56, no. 10, pp. 5419-5421, 2012.

[51] K. V. Kowdley, "Iron, hemochromatosis, and hepatocellular carcinoma," Gastroenterology, vol. 127, pp. S79-S86, 2004.

[52] D. Galaris, V. Skiada, and A. Barbouti, "Redox signaling and cancer: the role of "labile" iron," Cancer Letters, vol. 266, no. 1, pp. 21-29, 2008.

[53] M. Benhar, D. Engelberg, and A. Levitzki, "ROS, stress-activated kinases and stress signaling in cancer," EMBO Reports, vol. 3, no. 5, pp. 420-425, 2002.

[54] N. T. V. Le and D. R. Richardson, "The role of iron in cell cycle progression and the proliferation of neoplastic cells," Biochimica et Biophysica Acta, vol. 1603, no. 1, pp. 31-46, 2002.

[55] R. Sutherland, D. Delia, C. Schneider, R. Newman, J. Kemshead, and M. Greaves, "Ubiquitous cell-surface glycoprotein on tumor cells is proliferation-associated receptor for transferrin.," Proceedings of the National Academy of Sciences of the United States of America, vol. 78, no. 7, pp. 4515-4519, 1981.

[56] D. R. Richardson and E. Baker, "The uptake of iron and transferrin by the human malignant melanoma cell," Biochimica et Biophysica Acta, vol. 1053, no. 1, pp. 1-12, 1990.

[57] Z. K. Pinnix, L. D. Miller, W. Wang et al., "Ferroportin and iron regulation in breast cancer progression and prognosis," Science Translational Medicine, vol. 2, no. 43, Article ID 43ra56, 2010.

[58] B. J. Cherayil, "Iron and immunity: immunological consequences of iron deficiency and overload," Archivum Immunologiae et Therapiae Experimentalis, vol. 58, no. 6, pp. 407-415, 2010.
[59] S. A. Schwartz, A. Hernandez, and B. Mark Evers, "The role of NF-kappaB/IkappaB proteins in cancer: implications for novel treatment strategies," Surgical Oncology, vol. 8, pp. 143-153, 1999.

[60] Y.-P. Tsai and K.-J. Wu, "Hypoxia-regulated target genes implicated in tumor metastasis," Journal of Biomedical Science, vol. 19, no. 1, article 102, 2012.

[61] D. R. Richardson, "Therapeutic potential of iron chelators in cancer therapy," Advances in Experimental Medicine and Bio$\log y$, vol. 509, pp. 231-249, 2002.

[62] M. Ren, R. Rajendran, P. Ning et al., "Zinc supplementation decreases the development of atherosclerosis in rabbits," Free Radical Biology and Medicine, vol. 41, no. 2, pp. 222-225, 2006.

[63] N. Ishizaka, K. Saito, I. Mori, G. Matsuzaki, M. Ohno, and R. Nagai, "Iron chelation suppresses ferritin upregulation and attenuates vascular dysfunction in the aorta of angiotensin IIinfused rats," Arteriosclerosis, Thrombosis, and Vascular Biology, vol. 25, no. 11, pp. 2282-2288, 2005.

[64] O. Gursel, A. E. Kurekci, E. Tascilar et al., "Premature atherosclerosis in children with $\beta$-thalassemia major," Journal of Pediatric Hematology/Oncology, vol. 34, no. 8, pp. 630-634, 2012.

[65] S. Tajima, Y. Ikeda, K. Sawada et al., "Iron reduction by deferoxamine leads to amelioration of adiposity via the regulation of oxidative stress and inflammation in obese and type 2 diabetes KKAy mice," The American Journal of Physiology-Endocrinology and Metabolism, vol. 302, no. 1, pp. E77-E86, 2012.

[66] Y. Masuda, H. Ichii, and N. D. Vaziri, "At pharmacologically relevant concentrations intravenous iron preparations cause pancreatic beta cell death," The American Journal of Translational Research, vol. 6, no. 1, pp. 64-70, 2014.

[67] Y. Ikeda, I. Ozono, S. Tajima et al., "Iron chelation by deferoxamine prevents renal interstitial fibrosis in mice with unilateral ureteral obstruction," PLoS ONE, vol. 9, no. 2, Article ID e89355, 2014.

[68] S. Y. Wang, K. Singh, and S. C. Lin, "Glaucoma prevalence and the intake of iron and calcium in a population-based study," Current Eye Research, vol. 38, no. 10, pp. 1049-1056, 2013.

[69] P. Liu, M. Zhang, M. Shoeb et al., "Metal chelator combined with permeability enhancer ameliorates oxidative stress-associated neurodegeneration in rat eyes with elevated intraocular pressure," Free Radical Biology and Medicine, vol. 69, pp. 289-299, 2014.

[70] D. Vlahakos, N. Arkadopoulos, G. Kostopanagiotou et al., "Deferoxamine attenuates lipid peroxidation, blocks interleukin-6 production, ameliorates sepsis inflammatory response syndrome, and confers renoprotection after acute hepatic ischemia in pigs," Artificial Organs, vol. 36, no. 4, pp. 400-408, 2012.

[71] N. Arkadopoulos, D. Vlahakos, G. Kosotopanagiotou et al., "Iron chelation attenuates intracranial pressure and improves survival in a swine model of acute liver failure," Liver Transplantation, vol. 14, no. 8, pp. 1116-1124, 2008.

[72] G. G. Kostopanagiotou, K. A. Kalimeris, N. P. Arkadopoulos et al., "Desferrioxamine attenuates minor lung injury following surgical acute liver failure," European Respiratory Journal, vol. 33, no. 6, pp. 1429-1436, 2009.

[73] M. Minaiyan, E. Mostaghel, and P. Mahzouni, "Preventive therapy of experimental colitis with selected iron chelators and anti-oxidants," International Journal of Preventive Medicine, vol. 3, supplement 1, pp. S162-S169, 2012.

[74] P. G. Jamkhande, P. G. Chandak, S. C. Dhawale, S. R. Barde, P. S. Tidke, and R. S. Sakhare, "Therapeutic approaches to drug 
targets in atherosclerosis," Saudi Pharmaceutical Journal, vol. 22, no. 3, pp. 179-190, 2014.

[75] X.-M. Yuan and W. Li, "Iron involvement in multiple signaling pathways of atherosclerosis: a revisited hypothesis," Current Medicinal Chemistry, vol. 15, no. 21, pp. 2157-2172, 2008.

[76] D. E. Ferrara and W. R. Taylor, "Iron chelation and vascular function: in search of the mechanisms," Arteriosclerosis, Thrombosis, and Vascular Biology, vol. 25, no. 11, pp. 2235-2237, 2005.

[77] W. Kerner and J. Brückel, "Definition, classification and diagnosis of diabetes mellitus," Experimental and Clinical Endocrinology \& Diabetes, vol. 122, pp. 384-386, 2014.

[78] E. Oliveros, V. K. Somers, O. Sochor, K. Goel, and F. LopezJimenez, "The concept of normal weight obesity," Progress in Cardiovascular Diseases, vol. 56, no. 4, pp. 426-433, 2014.

[79] A. B. Farris and R. B. Colvin, "Renal interstitial fibrosis: mechanisms and evaluation," Current Opinion in Nephrology and Hypertension, vol. 21, no. 3, pp. 289-300, 2012.

[80] I. B. Torres, F. Moreso, E. Sarró, A. Meseguer, and D. Serón, “The interplay between inflammation and fibrosis in kidney transplantation," BioMed Research International, vol. 2014, Article ID 750602, 9 pages, 2014.

[81] G. Tezel, "Oxidative stress in glaucomatous neurodegeneration: mechanisms and consequences," Progress in Retinal and Eye Research, vol. 25, no. 5, pp. 490-513, 2006.

[82] P. M. C. K. Klouwenberg, D. S. Y. Ong, M. J. M. Bonten, and O. L. Cremer, "Classification of sepsis, severe sepsis and septic shock: The impact of minor variations in data capture and definition of SIRS criteria," Intensive Care Medicine, vol. 38, no. 5, pp. 811-819, 2012.

[83] E. Kemna, P. Pickkers, E. Nemeth, H. van der Hoeven, and D. Swinkels, "Time-course analysis of hepcidin, serum iron, and plasma cytokine levels in humans injected with LPS," Blood, vol. 106, no. 5, pp. 1864-1866, 2005.

[84] B. E. Holbein, "Iron-controlled infection with Neisseria meningitidis in mice," Infection and Immunity, vol. 29, no. 3, pp. 886891, 1980.

[85] D. L. Beaumier, M. A. Caldwell, and B. E. Holbein, "Inflammation triggers hypoferremia and de novo synthesis of serum transferrin and ceruloplasmin in mice," Infection and Immunity, vol. 46, no. 2, pp. 489-494, 1984.

[86] M. L. Kruzel, J. K. Actor, Z. Radak, A. Bacsi, A. SaavedraMolina, and I. Boldogh, "Lactoferrin decreases LPS-induced mitochondrial dysfunction in cultured cells and in animal endotoxemia model," Innate Immunity, vol. 16, no. 2, pp. 67-79, 2010.

[87] C. Ritter, A. Reinke, M. Andrades et al., "Protective effect of $\mathrm{N}$-acetylcysteine and deferoxamine on carbon tetrachlorideinduced acute hepatic failure in rats," Critical Care Medicine, vol. 32, no. 10, pp. 2079-2083, 2004.

[88] L.-Y. Guan, P.-Y. Fu, P.-D. Li et al., "Mechanisms of hepatic ischemia-reperfusion injury and protective effects of nitric oxide," The World Journal of Gastrointestinal Surgery, vol. 6, pp. 122-128, 2014.

[89] M. Kruszewski, "The role of labile iron pool in cardiovascular diseases," Acta Biochimica Polonica, vol. 51, no. 2, pp. 471-480, 2004.

[90] M. S. Paller and B. O. Hedlund, "Role of iron in postischemic renal injury in the rat," Kidney International, vol. 34, no. 4, pp. 474-480, 1988.

[91] A. Stamler, S. Y. Wang, D. E. Aguirre, F. W. Sellke, and R. G. Johnson, "Effects of pentastarch-deferoxamine conjugate on lung injury after cardiopulmonary bypass," Circulation, vol. 94, no. 9, pp. II358-II363, 1996.

[92] T. Ganz and E. Nemeth, "Iron sequestration and anemia of inflammation," Seminars in Hematology, vol. 46, no. 4, pp. 387393, 2009.

[93] C. E. Van Iperen, R. J. Kraaijenhagen, D. H. Biesma, Y. Beguin, J. J. M. Marx, and A. van de Wiel, "Iron metabolism and erythropoiesis after surgery," British Journal of Surgery, vol. 85, no. 1, pp. 41-45, 1998.

[94] M. Muñoz, J. A. García-Erce, and Á. F. Remacha, "Disorders of iron metabolism. Part 1: molecular basis of iron homoeostasis," Journal of Clinical Pathology, vol. 64, no. 4, pp. 281-286, 2011.

[95] G. Weiss and L. T. Goodnough, "Anemia of chronic disease," The New England Journal of Medicine, vol. 352, no. 10, pp. 1011-1023, 2005.

[96] K. H. Park, T. Sawada, T. Kosuge et al., "Surgical inflammation induces hepcidin production after abdominal surgery," World Journal of Surgery, vol. 36, no. 4, pp. 800-806, 2012.

[97] E. Gaffney-Stomberg and J. P. McClung, "Inflammation and diminished iron status: mechanisms and functional outcomes," Current Opinion in Clinical Nutrition and Metabolic Care, vol. 15, no. 6, pp. 605-613, 2012.

[98] A. Donovan, C. A. Lima, J. L. Pinkus et al., “The iron exporter ferroportin/Slc40al is essential for iron homeostasis," Cell Metabolism, vol. 1, no. 3, pp. 191-200, 2005.

[99] A. H. Laftah, B. Ramesh, R. J. Simpson et al., "Effect of hepcidin on intestinal iron absorption in mice," Blood, vol. 103, no. 10, pp. 3940-3944, 2004.

[100] E. Beutler, "Iron storage disease: facts, fiction and progress," Blood Cells, Molecules, and Diseases, vol. 39, no. 2, pp. 140-147, 2007.

[101] C. P. Doherty, "Host-pathogen interactions: the role of iron," Journal of Nutrition, vol. 137, no. 5, pp. 1341-1344, 2007.

[102] M. Cazzola and C. A. Finch, "Iron balance in thalassemia," Progress in Clinical and Biological Research, vol. 309, pp. 93-100, 1989.

[103] M. J. Pippard, S. T. Callender, G. T. Warner, and D. J. Weatherall, "Iron absorption and loading in $\beta$-thalassaemia intermedia," The Lancet, vol. 2, no. 8147, pp. 819-821, 1979.

[104] P. B. Walter, E. A. Macklin, J. Porter et al., "Inflammation and oxidant-stress in $\beta$-thalassemia patients treated with iron chelators deferasirox (ICL670) or deferoxamine: an ancillary study of the Novartis CICL670A0107 trial," Haematologica, vol. 93, no. 6, pp. 817-825, 2008.

[105] M. D. Scott, J. J. M. van den Berg, T. Repka et al., "Effect of excess $\alpha$-hemoglobin chains on cellular and membrane oxidation in model $\beta$-thalassemic erythrocytes," Journal of Clinical Investigation, vol. 91, no. 4, pp. 1706-1712, 1993.

[106] P. C. Adams, A. E. Kertesz, and L. S. Valberg, "Clinical presentation of hemochromatosis: a changing scene," The American Journal of Medicine, vol. 90, no. 4, pp. 445-449, 1991.

[107] J.-M. Fernández-Real, W. Ricart-Engel, E. Arroyo et al., "Serum ferritin as a component of the insulin resistance syndrome," Diabetes Care, vol. 21, no. 1, pp. 62-68, 1998.

[108] J. Wärnberg and A. Marcos, "Low-grade inflammation and the metabolic syndrome in children and adolescents," Current Opinion in Lipidology, vol. 19, no. 1, pp. 11-15, 2008.

[109] J. R. Peterson, R. V. Sharma, and R. L. Davisson, "Reactive oxygen species in the neuropathogenesis of hypertension," Current Hypertension Reports, vol. 8, no. 3, pp. 232-241, 2006. 
[110] T.-P. Tuomainen, K. Punnonen, K. Nyyssönen, and J. T. Salonen, "Association between body iron stores and the risk of acute myocardial infarction in men," Circulation, vol. 97, no. 15, pp. 1461-1466, 1998.

[111] G. J. Brewer, "Iron and copper toxicity in diseases of aging, particularly atherosclerosis and Alzheimer's disease," Experimental Biology and Medicine, vol. 232, no. 2, pp. 323-335, 2007.

[112] A. Sola, H. Peng, M. Rogido, and T.-C. Wen, "Animal models of neonatal stroke and response to erythropoietin and cardiotrophin-1," International Journal of Developmental Neuroscience, vol. 26, no. 1, pp. 27-35, 2008.

[113] K. Jellinger, W. Paulus, I. Grundke-Iqbal, P. Riederer, and M. B. H. Youdim, "Brain iron and ferritin in Parkinson's and Alzheimer's diseases," Journal of Neural Transmission-Parkinson's Disease and Dementia Section, vol. 2, no. 4, pp. 327-340, 1990.

[114] H. Seznec, D. Simon, C. Bouton et al., "Friedreich ataxia: the oxidative stress paradox," Human Molecular Genetics, vol. 14, no. 4, pp. 463-474, 2005.

[115] E. J. Kasarskis, L. Tandon, M. A. Lovell, and W. D. Ehmann, "Aluminum, calcium, and iron in the spinal cord of patients with sporadic amyotrophic lateral sclerosis using laser microprobe mass spectroscopy: a preliminary study," Journal of the Neurological Sciences, vol. 130, no. 2, pp. 203-208, 1995.

[116] K. D. Muirden and G. B. Senator, "Iron in the synovial membrane in rheumatoid arthritis and other joint diseases.", Annals of the Rheumatic Diseases, vol. 27, no. 1, pp. 38-48, 1968.

[117] M.-K. Lim, C.-K. Lee, Y. S. Ju et al., "Serum ferritin as a serologic marker of activity in systemic lupus erythematosus," Rheumatology International, vol. 20, no. 3, pp. 89-93, 2001.

[118] A. M. K. Choi and J. Alam, "Heme oxygenase-1: function, regulation, and implication of a novel stress-inducible protein in oxidant-induced lung injury," The American Journal of Respiratory Cell and Molecular Biology, vol. 15, no. 1, pp. 9-19, 1996.

[119] D. N. Seril, J. Liao, G. Y. Yang, and C. S. Yang, "Oxidative stress and ulcerative colitis-associated carcinogenesis: studies in humans and animal models," Carcinogenesis, vol. 24, no. 3, pp. 353-362, 2003.

[120] J. Cai, K. C. Nelson, M. Wu, J. Sternberg P., and D. P. Jones, "Oxidative damage and protection of the RPE," Progress in Retinal and Eye Research, vol. 19, no. 2, pp. 205-221, 2000.

[121] A. Wojas-Pelc and J. Marcinkiewicz, "What is a role of haeme oxygenase-1 in psoriasis? Current concepts of pathogenesis," International Journal of Experimental Pathology, vol. 88, no. 2, pp. 95-102, 2007.

[122] K. J. Davies, A. Sevanian, S. F. Muakkassah-Kelly, and P. Hochstein, "Uric acid-iron ion complexes. A new aspect of the antioxidant functions of uric acid," Biochemical Journal, vol. 235, no. 3, pp. 747-754, 1986.

[123] A. Mutti, M. Corradi, M. Goldoni, M. V. Vettori, A. Bernard, and P. Apostoli, "Exhaled metallic elements and serum pneumoproteins in asymptomatic smokers and patients with COPD or asthma," Chest, vol. 129, no. 5, pp. 1288-1297, 2006.

[124] L. W. Scheibel and A. Adler, "Antimalarial activity of selected aromatic chelators," Molecular Pharmacology, vol. 18, no. 2, pp. 320-325, 1980.

[125] E. D. Weinberg, “The hazards of iron loading," Metallomics, vol. 2, no. 11, pp. 732-740, 2010.

[126] C. M. Witmer, "Hematologic manifestations of systemic disease (including iron deficiency, anemia of inflammation and DIC)," Pediatric Clinics of North America, vol. 60, no. 6, pp. 1337-1348, 2013.
[127] S. Sazawal, R. E. Black, M. Ramsan et al., "Effects of routine prophylactic supplementation with iron and folic acid on admission to hospital and mortality in preschool children in a high malaria transmission setting: community-based, randomised, placebo-controlled trial," The Lancet, vol. 367, no. 9505, pp. 133143, 2006.

[128] I. Kochan, "The role of iron in bacterial infections, with special consideration of host-tubercle bacillus interaction.", Current Topics in Microbiology and Immunology, vol. 60, pp. 1-30, 1973.

[129] M. J. Murray, A. B. Murray, M. B. Murray, and C. J. Murray, "The adverse effect of iron repletion on the course of certain infections," British Medical Journal, vol. 2, no. 6145, pp. 1113-1115, 1978.

[130] I. T. Gangaidzo, V. M. Moyo, E. Mvundura et al., "Association of pulmonary tuberculosis with increased dietary iron," Journal of Infectious Diseases, vol. 184, no. 7, pp. 936-939, 2001.

[131] J. L. Sullivan, "Iron and the sex difference in heart disease risk," The Lancet, vol. 1, no. 8233, pp. 1293-1294, 1981.

[132] X.-M. Yuan and W. Li, "The iron hypothesis of atherosclerosis and its clinical impact," Annals of Medicine, vol. 35, no. 8, pp. 578-591, 2003.

[133] J. L. Sullivan, "Iron in arterial plaque: a modifiable risk factor for atherosclerosis," Biochimica et Biophysica Acta, vol. 1790, no. 7, pp. 718-723, 2009.

[134] J. L. Sullivan, "Is stored iron safe?" Journal of Laboratory and Clinical Medicine, vol. 144, no. 6, pp. 280-284, 2004. 


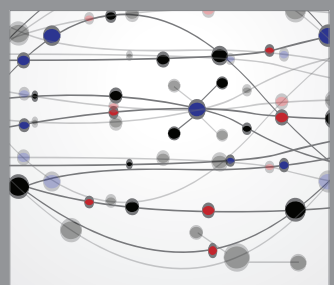

The Scientific World Journal
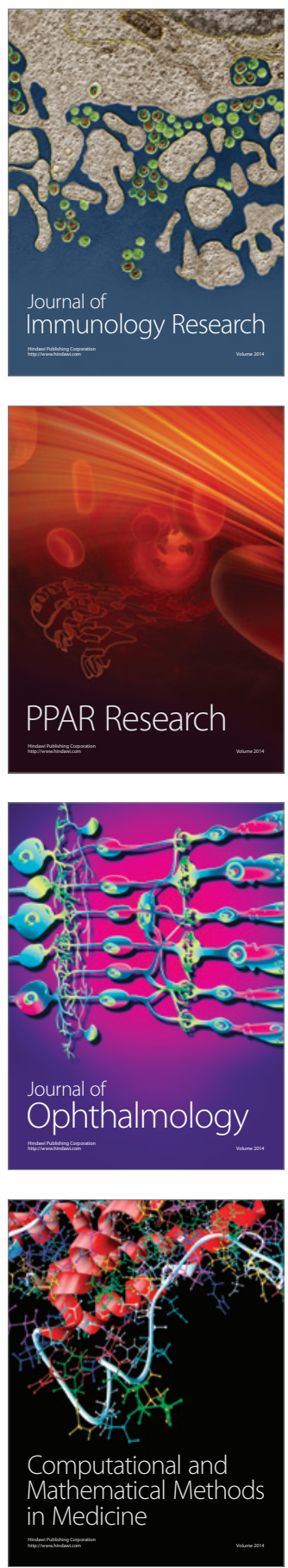

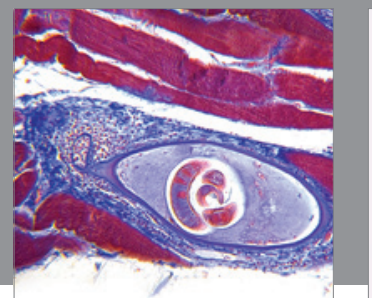

Gastroenterology

Research and Practice
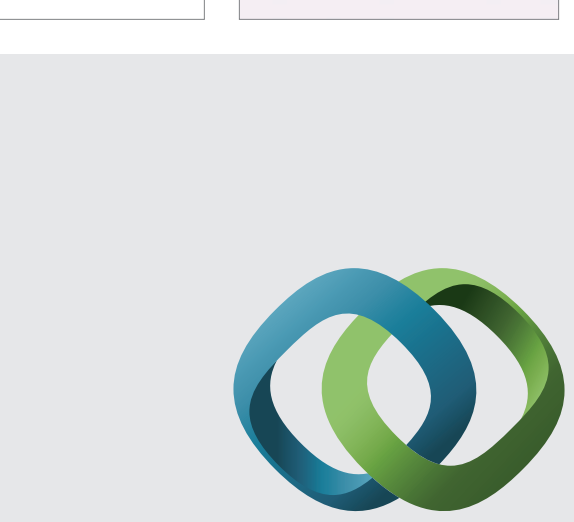

\section{Hindawi}

Submit your manuscripts at

http://www.hindawi.com
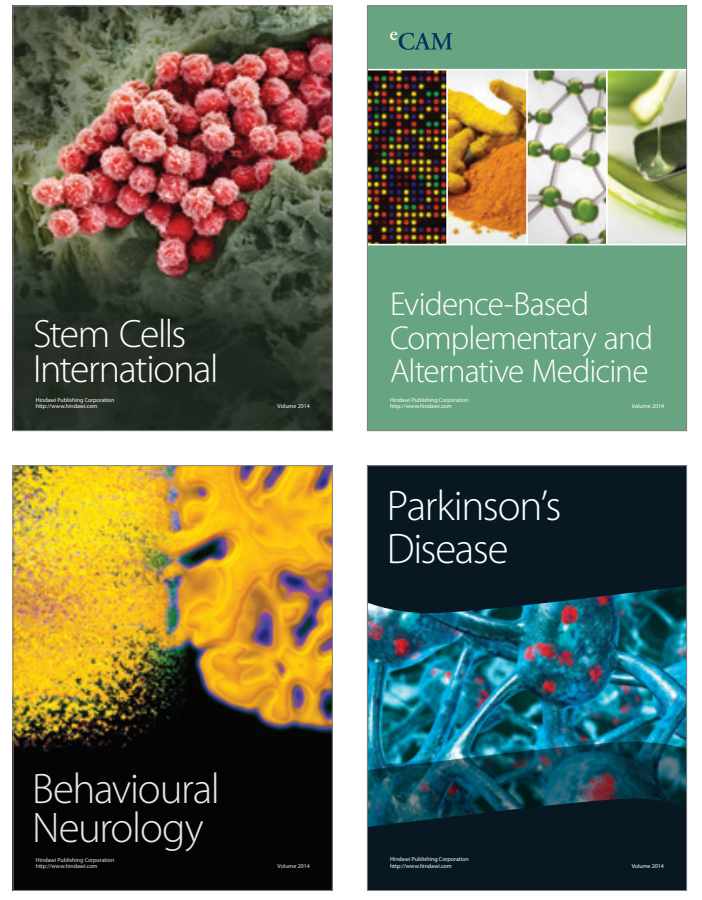
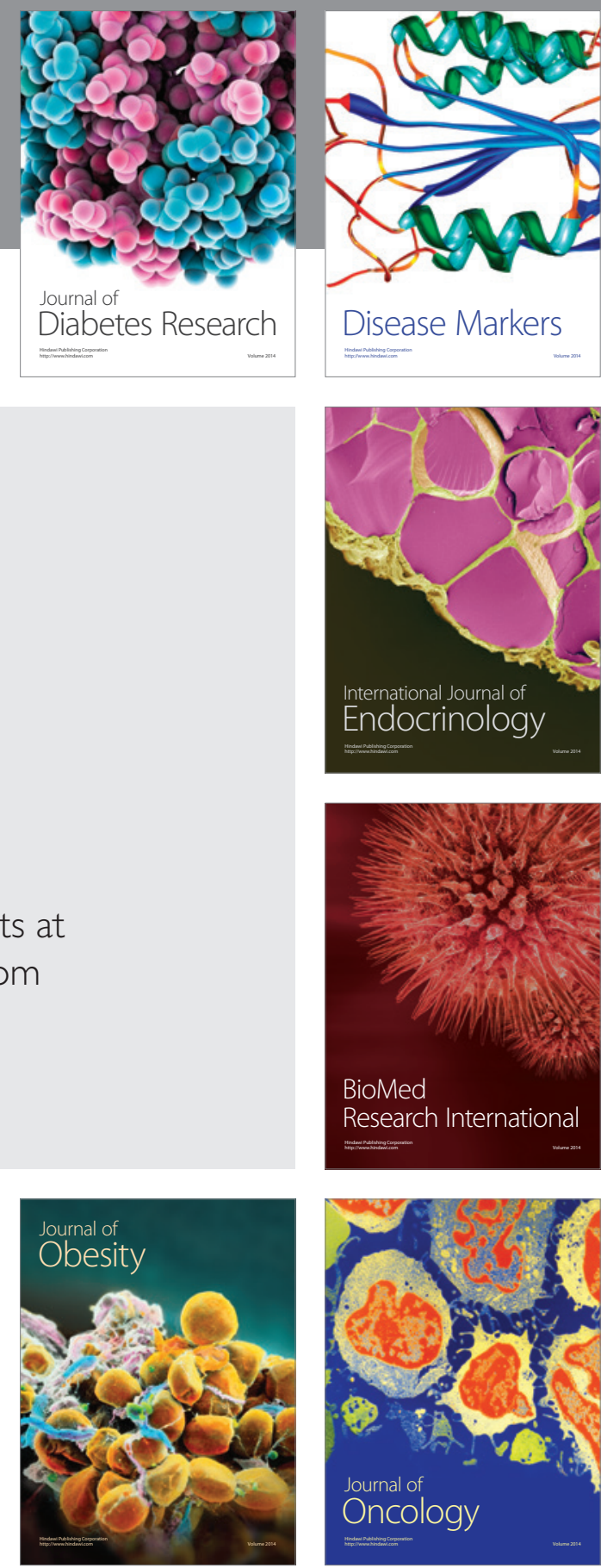

Disease Markers
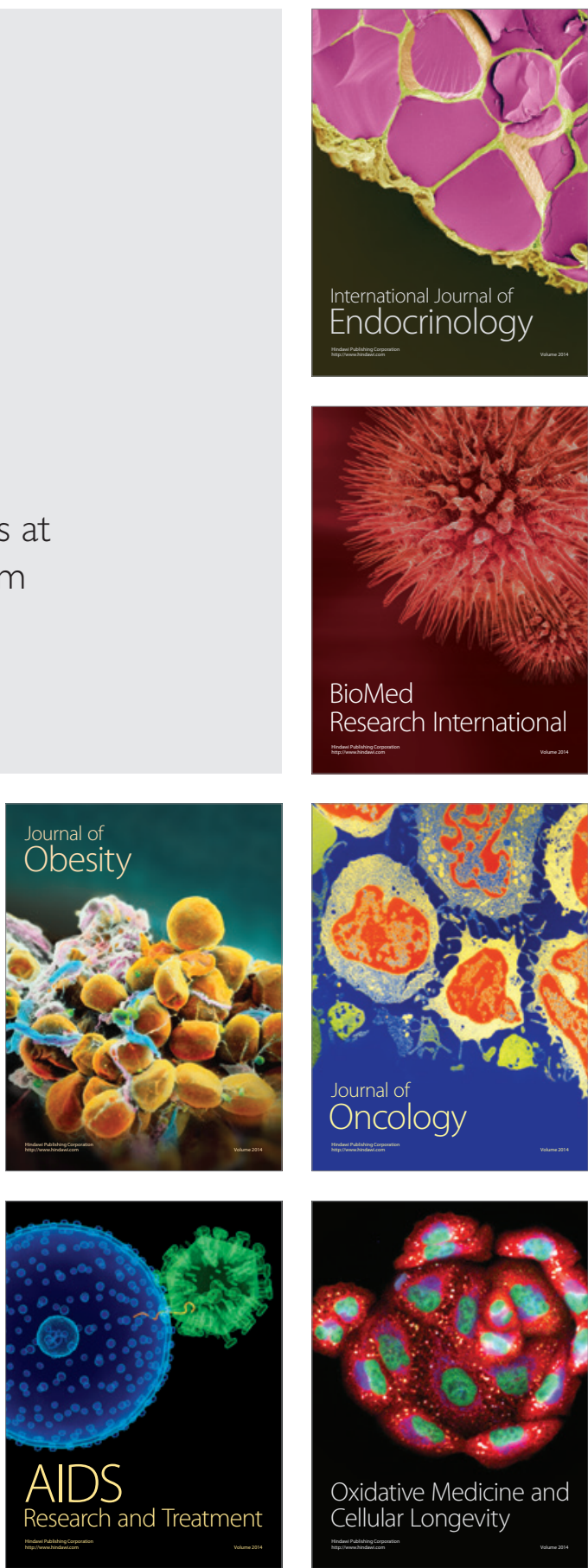